\title{
Identification of relevant project documents to 4D BIM uses for a synchronous collaborative decision support
}

\author{
Veronika Bolshakova $^{\mathrm{a}, \mathrm{b}, *}$, Annie Guerriero $^{\mathrm{c}}$, Gilles Halin ${ }^{\mathrm{a}, \mathrm{d}}$ \\ ${ }^{a} U M R n^{\circ} 3495$ Modèles et simulations pour l'Architecture et le Patrimoine Centre de Recherche en Architecture et Ingénierie - MAP-CRAI, 1, rue \\ Bastien Lepage, Nancy 54000, France \\ ${ }^{b}$ Centre National de la Recherche scientifique - CNRS, 3, rue Michel-Ange, Paris 75794, France \\ ${ }^{c}$ Luxembourg Institute of Science and Technology - LIST, Esch-sur-Alzette, Luxemburg \\ ${ }^{d}$ Université de Lorraine - UL, Nancy 54000, France
}

\begin{abstract}
Currently, the main use of 4D BIM is for visualization of the planned construction process. However, other uses have not yet been fully integrated into construction practices [1]. This paper presents a review of existing context to envisage ways of fostering the implementation of all 4D uses, and also to propose 4D BIM as a support to the decision-making process. Further the research will be completed by survey responses. In order to fully understand and efficiently implement 4D BIM models and methods, we need to develop a precise knowledge of which digital documents should be used and how they influence the decision-making process. This paper studies the convergence between 4D BIM uses and the project digital documents uses. We hypothesize that a construction simulation visualization of the 4D model is a useful source of information and a support for decision-making during a collaborative session. The visualized information and model development level correspond to the decision-making objectives [2].
\end{abstract}

(C) 2018 The Authors. Published by Diamond Congress Ltd., Budapest University of Technology and Economics Peer-review under responsibility of the scientific committee of the Creative Construction Conference 2018.

Keywords: BIM; 4D BIM; 4D BIM use; AEC project managment; collaboration; decision-making.

\section{Introduction}

Building Information Modeling/Management (BIM) implementation brings changes to many aspects of AEC project development. Along with new benefits and opportunities, AEC professionals are facing new challenges, such as the complexity of data and of work process organization as the project grows. Through the lens of the market view, AEC is dependent on a particular geographical location and related to it demands [3]. In addition to design and construction the current tendency is a frequency increase of additional services demands like facility management [4].

This paper firstly reviews 4D BIM diffusion and BIM project complexity in order to understand the current context and its limits. Secondly, it proposes 4D BIM uses summary, and their relevance to project development phase; in addition, project stakeholders roles on 4D BIM uses are questioned as well; a proposition of relevant complimentary documents to 4D BIM use concludes the section. The last section is dedicated to collaboration and decision-making problematics related to 4D BIM, and to further development methodology for a collective decision-making tool.

\section{BIM complexity and 4D BIM diffusion}

This section summarizes the of 4D BIM diffusion and French and Luxembourg local context. Also we introduce the BIM project complexity aspect and sociotechnical system.

Corresponding author: Bolshakova V. email: bolshakova@crai.archi.fr 


\subsection{Local BIM adoption and diffusion context for France and Luxembourg}

BIM diffusion studies with AEC professionals show their high interest in stronger collaboration or a belief in quality improvements due to BIM. However, more relevant feedback on projects is from firms with high level BIM implementation. Our study interest are France and Luxembourg. Luxembourg is developing a national BIM strategy and BIM execution plan [5], and has a strong initiative and support at the governmental level, where IT-barometer survey shows that firms were not very familiar with BIM (2014), the highest awareness among architects [6].

French digital initiative survey identified three main advantages of BIM perceived by professionals: stakeholders encouragement for stronger exchanges on a project; reduction of design errors; project quality improvement [7]. However, three main perceived disadvantages of BIM were identified as well, namely, the lack of internal skills, software costs, and finally the lack of standardization [7]. Report on French industry says that little more than 10\% of firms using BIM regularly [8], and the main concern is about implementation cost and complexity of BIM.

\subsection{BIM project complexity, socio-technical system and collaboration}

The previously mentioned complexity of BIM encompasses project complexity and organizational complexity [9]. In addition, the multiplicity and ambiguity can also be acknowledged as a part of the information processing approach to task complexity [10]. Figure 1 reviews these influences in detail.

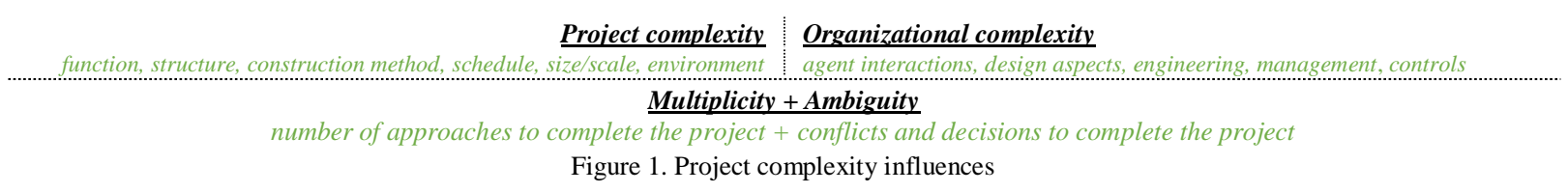

The complexity of a data organization is created by a number of project documents. 3D BIM model is often a core of the project, and it is linked to all other data which builds a number of dimensions into a holistic model, which covers the whole lifecycle of the project [11] [12]. 3D (x,y,z) + time management models are 4D, and additional to them information on costs stands as 5D. 6D, 7D stand for other resources. Such sophisticated models assure the full collaboration on transition to iBIM [13]. Also, the level of development, provides a progressive complexity increase to the system. Inevitably project document set depends on project type, on development phase and corresponding level of detail. Many BIM standards and guides (80\%[14]) offer methods and examples of documents.

With BIM the project stakeholders use a virtual model as a central source of information, design and management support. In this workflow process relies on a sociotechnical system [15][16]. Intelligent models and information management are the system technical core, it is enclosed by social elements: synchronous collaboration, coordinated work practices, institutional and cultural frameworks. The institution has its own intersocial order, which is nevertheless created by the interactions and influences among the institutional professionals [17]. The collaboration improvement is the second most cited benefit after the reduced errors and omissions [18]. These aspects point out the value of collaboration and workflow organization. Also, they are focused on a project quality as a central priority.

\subsection{D BIM diffusion}

During the last two decades the various studies have been conducted and often concluded that 4D BIM adoption rate stays relatively low [18][19][20]. Experiences from pilot projects have already indicated a successful use of 4D simulation for communication on construction sequencing for a number of projects in USA, Finland and China [21]. In Luxembourg a 5-th part of study respondents are familiar with 4D BIM [6]. Global report shows that many contractors have committed to an integration of model with schedule at design and pre-construction phases as one of their top 3 organization leverages (average 29\%, 9 largest markets), with 39\% in France [18]. 4D BIM in UK survey shows that more of $50 \%$ of participants presently use $4 \mathrm{D}$, with a higher level of personal use in organizations with a higher level of maturity; the adoption was an authority or a collective decision [22][23]. Australian research shows a basic level of 4D adoption, the companies tend to delegate 4D,5D-related tasks to external firms [24]. Every context has its own dynamics and specifics, but the global interest and shared problems are similar bonding for all the markets.

A BIM project itself, as a system, is non-linear and adaptive, it is also very interdependent with a significant number of influences involved, thus it must be approached with adaptive management. 


\section{4D BIM uses place at digital project development process}

4D BIM allies the virtual 3D model of the construction project with schedule, it occurs mostly at the pre-construction phase of development [25]. Projects with 4D BIM are no longer pilot projects but a common way of proceeding due to improved cost control and eliminates errors, whilst making scheduling and coordination more efficient.

\subsection{Project lifecycle and time management}

AEC project phases depend on a project context, and various phases have different labels and assignments by country, region, project type, contract type, etc. At the large scale, the project starts with the planning, passes through design and construction, and after being delivered has only maintenance interventions. Project risks to be considered during planning and design stages, and managed during construction [26].In addition, time management is introduced early to the project in order to provide proper resource, cost and liability management. At early stage project has an established program, with an already introduced time and cost approximate resources. While the project advances the planning, created by a group of professionals based on their experience, is developed [27]; The planning output would provide documented decisions on work organization. Which are a base for detailed scheduling with calculations, plans, resources and risks attached [27]; scheduling follows at pre-construction phase and becomes a dynamics schedule further during construction (Fig.2).

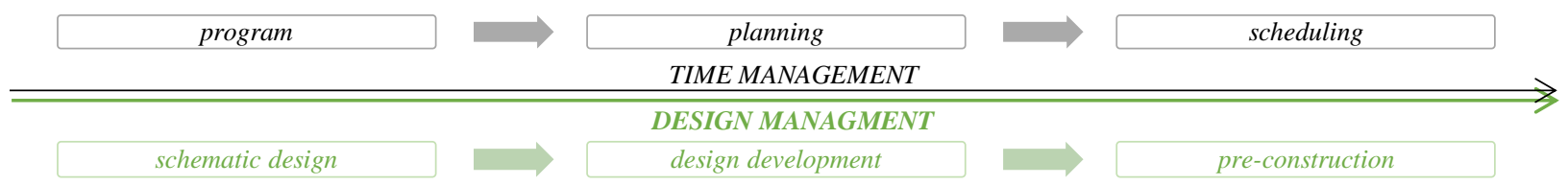

Figure 2. Time and design management elements of project development

The time management can approached with different methods [20]: Critical Pass Method, Program Evaluation and Review Technique, Linear Scheduling Method, Line of Balance, Last Planner System, Critical Chain Method, Virtual Construction. However, an adaptive dynamic time management may combine these approaches to find the best fit for each section of the project [27]. Program and early planning start at the same time as the concepts and design, once the project shape is defined the time aspect is introduced and developed, and recourses follow it. An efficient dynamic schedule assures review, revision, monitoring, updates and impacts. For a complex BIM project, a single approach would not be efficient, thus early anticipation and a holistic, systematic approach should be implemented.

\subsection{Project lifecycle and BIM management}

The design development and project management, in the case of BIM project, would be closely related and guided with BIM management. According to the Managing design process roadmap, presented by Gu and London [28], there are steps related to BIM process setups (identification of roles, phases, activities, tools, etc.) preceding the design phase. Also various disciplines have their role in project development (Architecture, Engineering, Cost Management, Quality Control, Time Management, etc.) [27], and one of BIM challenges will be requirement to connect people to project information [29]. Often project is developed by specialists who have not been working together previously, where every firm develops their part of the common project, but since they are separate units, they do not integrate fully into a collaborative framework [4]. Thus, a prepared and project customized organization of the BIM process with a well-adapted framework are essential for efficient design, time and cost, and construction management.

\subsection{From $3 D$ to $4 D$ concept}

Through the evolution of the project the BIM model evolves as well, gaining new data, new connections, new actors. Since "conceptually 4D CAD represents a type of graphic simulation of a process" [30], it is important to understand what is actually represented in 4D. The dimensions are Time and 3D, and while visualizing the 4D, we still see the 3D and time which are represented through the animation and/or a time diagram, progress line, task list, etc. An added value is a new component created by a relation established between the elements of the 3D model and Tasks, which share and combine assigned data, and technically create their own new concept of a 4D relationship (Table 1.). 
Table 1. Dimensions and Data concepts as parts of 4D model

\begin{tabular}{|c|c|c|c|c|}
\hline & Time management & 3D Model & 4D Model & $\mathrm{nD}$ \\
\hline Dimension & Time & $X, Y, Z$ geometry $=3 D$ & $3 D+$ Time $=4 D$ & $\underline{4 D+N}$ \\
\hline \multirow[t]{2}{*}{ Data } & Task: & Spatial element: & 4D relationship: & $\mathrm{nD}$ network \\
\hline & $\begin{array}{l}\text { - } \text { ID time } \\
\text { - } \text { Type time } \\
\text { - } \text { Start/End/Progress } \\
\text { - Resources T } \\
\text { - Risks, etc. }\end{array}$ & $\begin{array}{l}\text { - ID element } \\
\text { - Type element } \\
\text { - Resources } M \\
\text { - Prescriptions }\end{array}$ & $\begin{array}{l}\text { - } \frac{\text { Progress }}{\text { - }} \text { ID }(\underline{\text { time }}+\text { element }) \\
\text { - } \underline{\text { Type }}(\mathrm{time}+\text { element }) \\
\text { - } \underline{\text { Resources }}(\underline{\mathrm{T}}+M) \\
\text { - } \underline{\text { Risks }} \\
\text { Prescriptions }\end{array}$ & $\begin{array}{l}\text { - Holistic system of elements }+ \\
\text { time }+ \text { costs }+ \\
\text { other project data }\end{array}$ \\
\hline
\end{tabular}

\section{4. $4 D$ BIM uses}

Study of 4D BIM uses follows a more general study of BIM uses, where "BIM Use: A method or strategy of applying Building Information Modeling during a facility's lifecycle to achieve one or more specific objectives." [31].

Guerriero et al. [1] propose following 4D BIM uses: 4D Scheduling, 4D Clash Detection, 4D Safety Management, 4D Site Lay-out \& Environment Management, 4D Constructability Management, 4D Monitoring and 4D Visual communication as a core use. One of 4D BIM major benefits is information accessibility and clear visualization - all actors have access to a 3D model and to an attached schedule, to simulations and analysis. All the uses involve stakeholders' expertise and collaboration.

4D BIM uses potential introduction and implementation by project phases and with a corresponding LOD is summarized in Figure.3. The operation and maintenance phase is not in a scope of this research due to the phase specifics and main relevance in a domain of facility management.

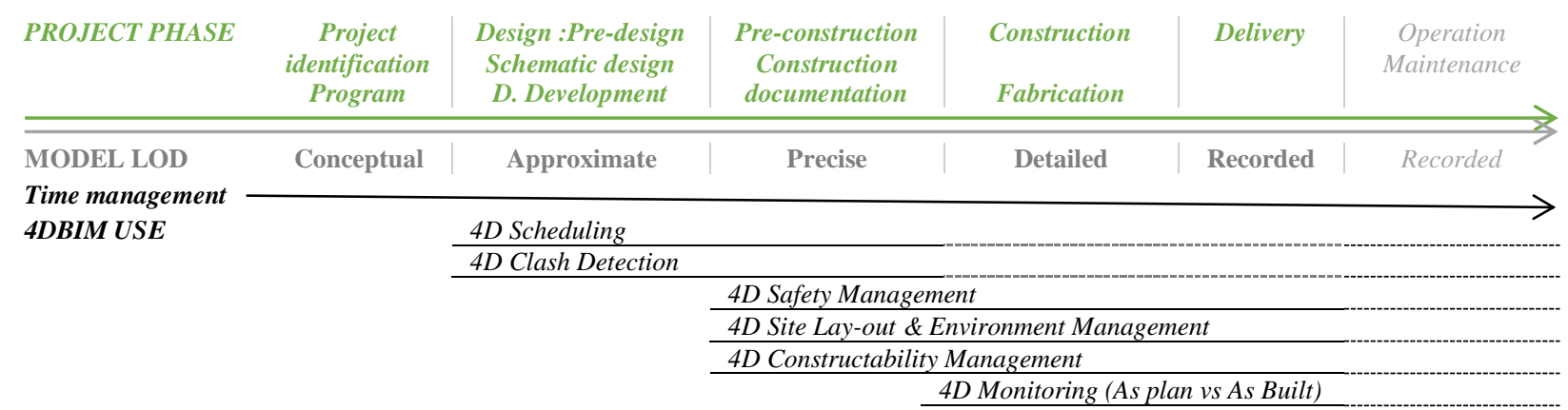

Figure 3. Project phases and model LOD, 4D BIM use potential introduction

4D BIM can be integrated at any phase, when the dimensions and accompanying data are available, sometimes it even may be helpful on negotiation stage. An interesting fact is that survey respondents with less BIM experience tend to identify visualization as a major benefit from BIM, and more experienced respondents tend to find the value in work process organization. In the same way 4D BIM value is perceived as a visualization, however other potential uses have not yet been put in a common practice. It is also often seen as a complementary scheduling instrument [32].

\subsection{D BIM uses and project stakeholders involvement}

The role and involvement of stakeholders are dependent on a project and contract types, on workflow organization. However, a global pattern is predictable to scheme the main workflow components and stakeholder involvement [33]. Table 2 presents a proposition of involvement and influences of stakeholders vis-à-vis 4D BIM uses synthesis.

Stakeholders use 4D BIM and interact with it in various ways, it depends on a project phase. 4D visualization use has a transversal place in project lifecycle, it supports every other use, all the stakeholders benefit from it. The table proposes Responsibility or Participant stakeholders roles, with nuances (responsible validator RV or coordinator RC; participant producer PP, expert PE or reader PR [34]).

For example 4D Scheduling is relevant on a Design and Pre-constriction phases (it is followed by 4D Monitoring during the construction), and involves firstly the project management and a client meeting 3D model creations. Client has RV and PR responsibilities, the process is led by experience of architect and engineers, BIM manager assists to place the methodology and collaboration. Contractor has a secondary role on a design phase 4D scheduling but takes a responsibility of coordination on a pre-construction phase. 
Table 2. 4D BIM uses and Stakeholders operating roles, influences \& interactions Stakeholders

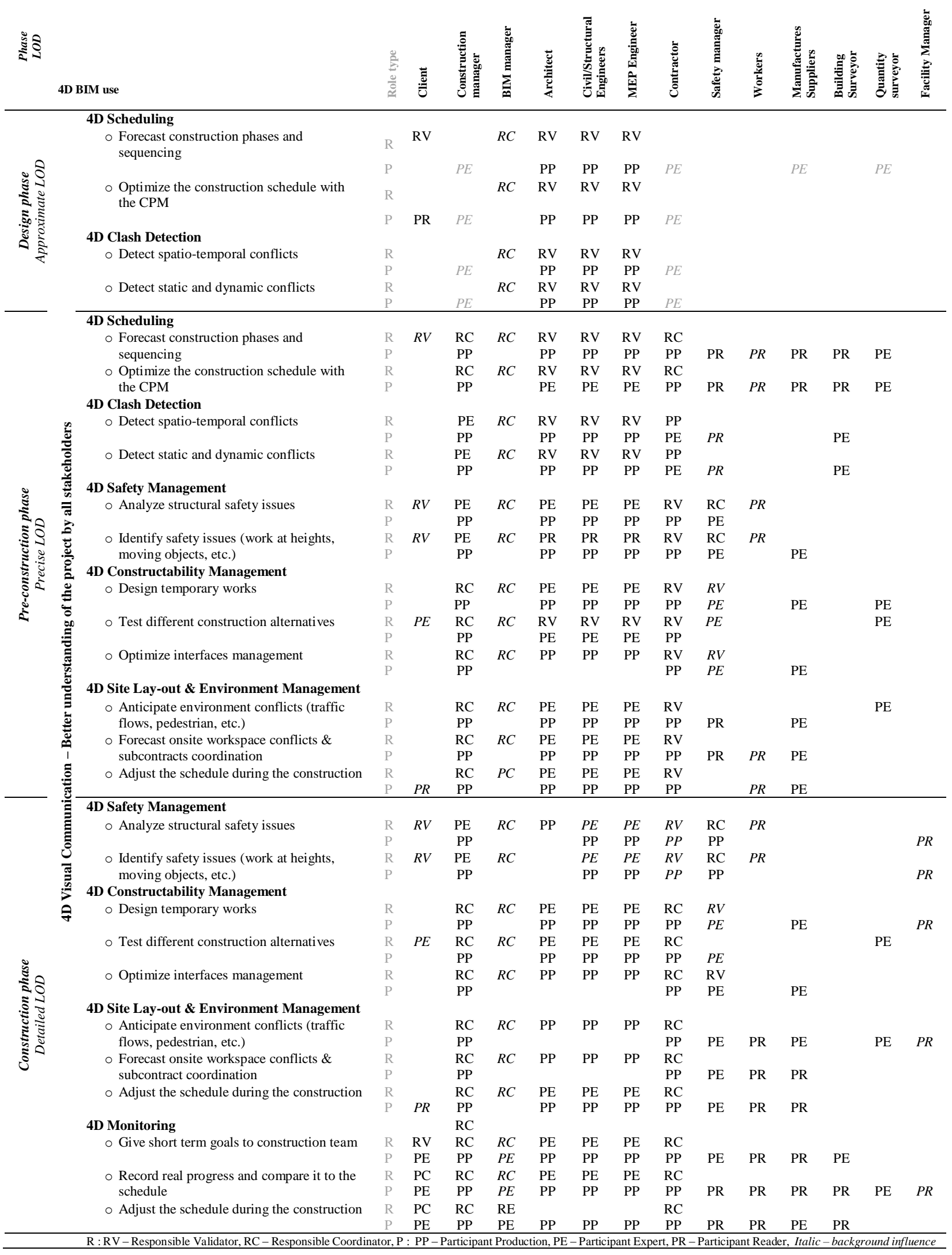


Multiple competences involvement into decision-making on a 4D BIM use must be beneficial in terms of error detection and communication to increase construction efficiency. An important team role is held by construction manager and contractor, who assemble many responsibilities on pre-construction and construction phases. 3D model creators have many responsibilities and influences as well, they have more responsibilities in the beginning of the project, and then have to update their models through all the phases (RV \& PP roles). Finally, the client has more of an influence on input data (time and costs related), rather than on construction processes itself.

Once responsibilities and involvement links are summarized, we may look for a project data which would be relevant at the decision-making session, and will offer actors sufficient and complete information on a project (Tab.3). The core of the session support documents is a $4 \mathrm{D}$ relationship of 3D model and time management data, in addition to the project stakeholders must have access to other project documents.

Table 3. 4D BIM uses and Project documents for decision-making support

\begin{tabular}{|c|c|c|c|c|}
\hline & & 4D BIM use & 4D Model & Complementary project documents \\
\hline 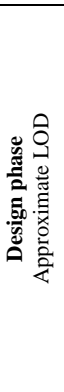 & & $\begin{array}{l}\text { 4D Scheduling } \\
\circ \text { Forecast construction phases and sequencing } \\
\circ \text { Optimize the construction schedule with the CPM }\end{array}$ & $\begin{array}{l}\text { 3D models (Archi, } \\
\text { Structural, MEP, Civil) } \\
\text { from early design to } \\
\text { design development } \\
\text { Time management } \\
\text { program or planning } \\
\text { with estimation of time } \\
\text { and required } \\
\text { construction recourses } \\
\text { (general stages) }\end{array}$ & $\begin{array}{l}\text { - State of terrain (plans, permits, environment, soils study) } \\
\text { - Program and budget from client } \\
\text { - Project volume, specifications (generic numbers, plans) } \\
\text { - Project principal stakeholders (generic list) } \\
\text { - Construction methodology choice } \\
\text { - General requirements on project delivery, program } \\
\text { - Calendar events intersecting with construction } \\
\text { - Collaboration protocol } \\
\text { - Models assembled } \\
\text { - Rules of conflict detection } \\
\text { - Estimations of charges } \\
\text { - Collaboration protocol, roles, charts }\end{array}$ \\
\hline 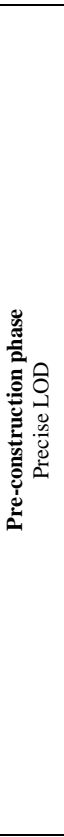 & 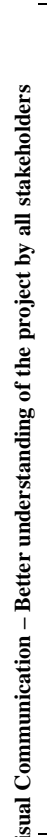 & $\begin{array}{l}\text { 4D Safety Management } \\
\circ \text { Analyze structural safety issues } \\
\circ \text { Identify safety issues (work at heights, moving } \\
\text { objects, etc.) } \\
\text { 4D Constructability Management } \\
\circ \text { Design temporary works } \\
\circ \text { Test different construction alternatives } \\
\circ \text { Optimize interfaces management } \\
\text { 4D Site Lay-out \& Environment Management } \\
\circ \text { Anticipate environment conflicts (traffic flows, } \\
\text { pedestrian, etc.) } \\
\circ \text { Forecast onsite workspace conflicts \& subcontracts } \\
\text { coordination } \\
\circ \text { Adjust the schedule during the construction }\end{array}$ & $\begin{array}{l}\text { 3D models (Archi, } \\
\text { Structural, MEP, Civic) } \\
\text { well established and } \\
\text { detailed } \\
\text { Time management } \\
\text { planning with estimation } \\
\text { of time and required } \\
\text { construction recourses } \\
\text { which is transformed } \\
\text { into a precise } \\
\text { construction scheduling } \\
\text { (tasks, elements, dates; } \\
\text { construction firm, } \\
\text { equipment and material } \\
\text { requirements) }\end{array}$ & $\begin{array}{l}\text { - Terrain preparations (plans, permits, environment, soils study) } \\
\text { - Project volume, specifications and quantifications } \\
\text { - Details (constructing technology techniques, tools, competence) } \\
\text { - Plans and technical details of the project } \\
\text { - Detailed requirements on project delivery } \\
\text { - Project stakeholders roles and interventions limits } \\
\text { - Stakeholders calendars and recourses } \\
\text { - Collaboration protocol, roles, charts } \\
\text { - Economic and management risks and quantifications } \\
\text { - Rules of conflict detection } \\
\text { - Plans and technical details of the project } \\
\text { - Construction methodology details } \\
\text { - Estimations of charges } \\
\text { - Collaboration protocol, roles, charts } \\
\text { - Preparations of construction terrain (plans, permits, works) } \\
\text { - Project volume, specifications and quantifications } \\
\text { - Construction methodology details } \\
\text { - Plans and technical details of the project } \\
\text { - Project stakeholders roles and interventions limits } \\
\text { - Stakeholders calendars and recourses } \\
\text { - Collaboration protocol, roles, charts } \\
\text { - Security protocols, contracts, insurances, controls } \\
\text { - Requirements on project delivery } \\
\text { - Safety control protocols } \\
\text { - Economic and management risks and quantifications }\end{array}$ \\
\hline 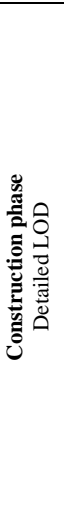 & 字 & $\begin{array}{l}\text { 4D Safety Management } \\
\circ \text { Analyze structural safety issues } \\
\circ \text { Identify safety issues (work at heights, moving } \\
\text { objects, etc.) } \\
\text { 4D Constructability Management } \\
\circ \text { Design temporary works } \\
\circ \text { Test different construction alternatives } \\
\circ \text { Optimize interfaces management } \\
\text { 4D Site Lay-out \& Environment Management } \\
\circ \text { Anticipate environment conflicts (traffic flows, } \\
\text { pedestrian, etc.) } \\
\circ \text { Forecast onsite workspace conflicts \& subcontract } \\
\text { coordination } \\
\text { 4D Mdjust the schedule during the construction } \\
\circ \text { Give short term goals to construction team } \\
\circ \text { Record real progress and compare it to the schedule } \\
\circ \text { Adjust the schedule during the construction }\end{array}$ & $\begin{array}{l}\text { 3D models (Archi, } \\
\text { Structural, MEP, Civic) } \\
\text { initial and ongoing, as- } \\
\text { build } \\
\text { Time management as a } \\
\text { precise dynamic } \\
\text { construction scheduling } \\
\text { (on-going tracking, } \\
\text { risks, milestones, logs) }\end{array}$ & $\begin{array}{l}\text { - Project diary (log, reports, photos, scans, exchanges) } \\
\text { - Updates on construction terrain with work progress details } \\
\text { - Quantifications and supply update } \\
\text { - Construction methodology details } \\
\text { - Update on human and tools recourses } \\
\text { - Project stakeholders roles and interventions limits } \\
\text { - Stakeholders calendars and recourses } \\
\text { - Collaboration protocol, roles, charts } \\
\text { - Security protocols, contracts, insurances, controls } \\
\text { - Plans and technical details of the project } \\
\text { - Requirements on project delivery } \\
\text { - Economic and management risks } \\
\text { - Project diary (log, reports, photos, scans, exchanges) } \\
\text { - Requirements lists (e.g. responsible construction firm, materials, equipment) } \\
\text { - Collaboration protocols, contracts } \\
\text { - Economic and management risks }\end{array}$ \\
\hline
\end{tabular}




\section{Digital continuum and collective decision-making support research}

\subsection{D BIM and collaborative software interfaces}

The complexity increases through a project lifecycle, and it places 3D into a center of exchanges. So it gathers and connects numerous documents, some of them are originally digital and some are digitalized in order to get integrated into BIM process. However, the continuity of digital workflow and BIM workflow is often interrupted at the moment of information extraction in order to prepare a well-corresponding documents to decision-making objective. Thus, to avoid information losses, to optimize work, to avoid redundancy of tasks and to keep the connection to BIM data, it is important to integrate fully collaborative and interoperability offering tools into the equipment set for decision-making.

Table 4. User interface and BIM Viewers for 3D and 4D

\begin{tabular}{lccc}
\hline & \multicolumn{2}{c}{ Individual collaborative asynchronous Interface } & Collective collaborative synchronous Interface \\
\cline { 2 - 4 } BIM software tool type & $3 D$ & $4 D$ & $3 D$ \\
\hline BIM Modelers & $\bullet$ & $\bullet$ & Currently no BIM solution \\
BIM models Checkers & $\bullet$ & integrated into modelers & \\
BIM model Viewers & $\bullet$ &
\end{tabular}

Software tools are important part of BIM socio-technical system, there are several options and purpose classes: services, catalogs, servers, viewer, modelers, mobile, checkers, management, simulation, communication, publishing, query, utilities [35]. Table 4 compares selected three BIM software tool types (which have direct connection to 3D information visualization and modification), and interface types, in order to understand existing interface limitations concerning collective interaction options. A distant collaboration via cloud server is available with a single user interface. However there is no fully collaborative solution for a synchronous collaboration, in addition, the interoperability data formats have not yet integrated the time dimension into a single model with 3D [33].

Moreover, the 4D model interactions are mostly single-user targeted, thus the multi-user aspect is an important feature to be developed. The digital documents interaction interface must stay digital to avoid incorrect interpretation of the information and data losses, and to offer the best usability to the session participants. Such ease of access and low appropriation time with a tool is offered by natural user interfaces (NUI), we propose to implement a multi-touch collaborative table and wall within a NUI as session equipment. NUI fosters the convergence of 4D uses with project documents and gives an ease of interactions for decision-making.

\subsection{Further research for collective decision-making support configuration}

Being a part of 4D Collab ANR/FNR research project, this paper participates a global approach (Fig. 3 illustrates methodology steps). To develop a decision-making support configuration and collaboration scenarios, we have already conducted a series of experiments with existing collaboration tools (multi-touch screens and "Shariiing" by Immersion https://www.shariiing.com) with professionals, who worked by design development scenario. The experiments have resumed current limits of collaboration solution and users need for more natural and industry adapted interactions [36]. Next comes the current proposal of relations between project phase and 4D BIM use, and 4D BIM uses relation to project documents, as well as the project stakeholders roles and influences on the uses. Following step will evaluate this summery with a series of AEC professionals interviews, who provide us with real practices and experiences vison. Afterwards, the decision-making tools evaluation and specification will complete a synchronous collaborative tool proposition. Finally, decision-making sessions within a use of 4D, touch table and Shariiing will resume the research.

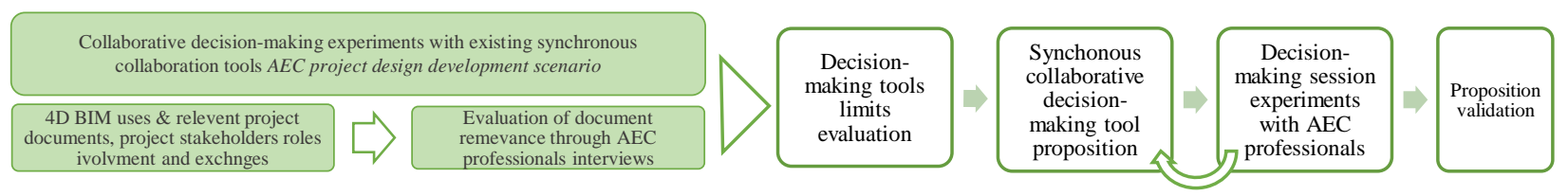

Figure 4. Summary of methodology decision-making support research and development proposition

\section{Conclusion}

4D BIM becomes a part of common practices, and besides the improvements of project visualization it offers other uses. 4D BIM uses implementation must be customized to a project development phase. Some of the uses are available already on design phase, but the principal field of implementation is on pre-construction. The uses are not limited to 
planning activates nor clash detection, but offer an access to construction management and monitoring. Stakeholders roles and responsibilities evolve through the project lifecycle, their role in 4D BIM use and decision-making changes as well. Every decision-making session with a 4D BIM use as an approach has a specific objective and this objective attendance requires a stakeholders' intervention and relevant decision support information on a project. We observe that even with a full information 3D model and time management 4D relation there is still a constant need for additional project documents. The set of these documents alters on the use and on project phase.

The 4D and a set of other digital documents at a decision-making session provide the information support. However the session participants must have an access to relevant interactions with the project information as well in order to keep fluidity of collaboration and better understanding of the project. Therefore, with 4D Collab research project, we continue to progress to develop a configuration for relevant collective synchronous decision-making support, optimized for AEC specific needs and 4D BIM uses in particular.

\section{Acknowledgements}

This study was developed under the patronage of "Agence Nationale de la Recherche" No.ANR-16-CE10-000602 (FR) and "Fonds National de la Recherche" (LU), as a part of the international research project 4D Collab.

\section{References}

[1] A. Guerriero, S. Kubicki, F. Berroir, C. Lemaire, BIM-enhanced collaborative smart technologies for LEAN construction processes, 2017 Int. Conf. Eng. Technol. Innov. (2017) 1063-1070. doi:10.1109/ICE.2017.8279994.

[2] C. Boton, S. Kubicki, G. Halin, 4D / BIM simulation for pre-construction and construction scheduling. Multiple levels of development within a single case study, Creat. Constr. Conf. 2015 (2015) 500-505. doi:10.13140/RG.2.1.1941.3603.

[3] P.M. Hillebrandt, Economic Theory and the Construction Industry, Third edit, Palgrave Macmillan UK, London, 2000. doi:10.1057/9780230372481.

[4] Dodge Data \& Analytics, SmartMarket Report The Business Value of BIM for Infrastructure, SmartMarket Report, Bedford, 2017.

[5] Eurostat, European Construction Sector Observatory Country profile Luxembourg, 2018.

[6] S. Kubicki, C. Boton, IT Barometer Survey in Luxembourg: First results to understand IT innovation in Construction sector, in: T. Park, T. Kang, Y. Lee, K. Seo (Eds.), Comput. Civ. Build. Eng., American Society of Civil Engineers, Reston, VA, 2014: pp. 423-430. doi:10.1061/9780784413616.053.

[7] PTNB, Plan Transition Numérique dans le Bâtiment - Rapport d'etape, 2017. http://www.batiment-numerique.fr/.

[8] European Construction Sector Observatory - European Commission, http://ec.europa.eu/growth/sectors/construction/observatory/ (acc. March 26, 2018).

[9] H.L. Wood, P. Piroozfar,Understanding complexity in the AEC industry,Proc. 29th Annu. Assoc. Res. Constr. Manag. Conf. ARCOM 2013.(2014) 859-869.

[10] D.J. Campbell, Task Complexity: A Review and Analysis., Acad. Manag. Rev. 13 (1988) 40-52. doi:10.5465/AMR.1988.4306775.

[11] A. Lee, S. Wu, A. Marshall-Ponting, G. Aouad, J. Tah, R. Cooper, C. Fu, nD modelling - a driver or enabler for construction improvement ? RICS Research paper series, RICS Res. 5 (2006) 16

[12] T. Hartmann, J. Gao, M. Fischer, Areas of application for 3D and 4D models on construction projects, J. Constr. Eng. (2008) 776-785.

[13] BSI, Specification for information management for the operational phase of assets using building information modelling, (2014).

[14] R. Sacks, U. Gurevich, P. Shrestha, A review of Building Information Modeling Protocols, Guides and Standards for Large Construction Clients, (2016) 479-503.

[15] WPS Group \& Kaoris Future, Truths about BIM, 2018.

[16] E. Sackey, A Sociotechnical Systems Analysis of Building Information Modelling (STSaBIM) Implementation in Construction Organisations, (2014) 12-22.

[17] M. Jacobsson, H.C.J. Linderoth, S. Rowlinson, The role of industry: an analytical framework to understand ICT transformation within the AEC industry, Constr. Manag. Econ. 35 (2017) 611-626. doi:10.1080/01446193.2017.1315148.

[18] McGraw Hill Construction, SmartMarket Report The business value of BIM for construction in major global markets: How Contractors Around the World Are Driving Innovation With Building Information Modeling, Bedford, 2014. http://damassets.autodesk.net/content/dam/autodesk/www/solutions/buildinginformation-modeling/construction/business-value-of-bim-for-construction-in-global-markets.pdf.

[19] A. Mahalingam, R. Kashyap, C. Mahajan, An evaluation of the applicability of 4D CAD on construction projects, Autom. Constr. 19 (2010) $148-159$.

[20] C. Boton, Conception de vues métiers dans les collecticiels orientés service. Vers des multi-vues adaptées pour la simulation collaborative 4D/nD de la construction, (2013) 317.

[21] T. Hartmann, J. Gao, M. Fischer, Areas of application for 3D and 4D models on construction projects, J. Constr. Eng. .... (2008) 776-785.

[22] B. Gledson, Investigating the diffusion of 4D BIM Innovation, Proc. 31st Annu. ARCOM Conf. (2015) 641-650. doi:10.13140/RG.2.1.4669.0165.

[23] B.J. Gledson, D. Greenwood, The adoption of 4D BIM in the UK construction industry: an innovation diffusion approach, Eng. Constr. Archit. Manag. 24 (2017) 950-967. doi:10.1108/ECAM-03-2016-0066.

[24] K. Pyung, K. Lecturer, T. Ma, S. Lecturer, A.S. Baryah, C. Zhang, K.M. Hui, Investigation of Readiness for 4D and 5D BIM Adoption in the Australian Construction Industry, Manag. Rev. An Int. J.11 (2016) 43-65.

[25] Z. Hu, J. Zhang, BIM- and 4D-based integrated solution of analysis and management for conflicts and structural safety problems during construction: 2 . Development and site trials, Autom. Constr. 20 (2011) 155-166. doi:10.1016/j.autcon.2010.09.013.

[26] Y. Zou, A. Kiviniemi, S.W. Jones, A review of risk management through BIM and BIM-related technologies, Saf. Sci. 97 (2017) 88-98. doi:10.1016/j.ssci.2015.12.027.

[27] CIOB (The Chartered Institute of Building), Guide to good practice in the managment of time in major projects. DYnamic time modelling, Second edi, WileyBlackwell, Hoboken, HJ, USA.

[28] N. Gu, K. London, Understanding and facilitating BIM adoption in the AEC industry, Autom. Constr. 19 (2010) 988-999. doi:10.1016/j.autcon.2010.09.002.

[29] K.M. Kensek, Building Information Modeling, First edit, Routledge, Abingdon, 2014.

[30] K. McKinney, J. Kim, M. Fischer, C. Howard, Interactive 4D-CAD, Proc. Third Congr. Comput. Civ. Eng. 135 (1996) 1261.

[31] R.G. Kreider, J.I. Messner, The Uses of BIM: Classifying and Selecting BIM Uses, Pennsylvania State Univ. (2013) http://bim.psu.edu/Uses/the_uses_of_BIM.pdf

[32] C.N. Rolfsen, C. Merschbrock, Acceptance of Construction Scheduling Visualizations: Bar-charts, Flowline-charts, or Perhaps BIM?, Procedia Eng. 164 (2016) 558-566. doi:10.1016/j.proeng.2016.11.658.

[33] M. Kassem, N. Iqbal, G. Kelly, S. Lockley, N. Dawood, Building Information Modelling : Protocols for Collaborative Design Processes, ITcon. 19 (2014) 126149. http://www.itcon.org/data/works/att/2014_7.content.00672.pdf.

[34] G. Halin, D. Hanser, O. Malcurat, J.C. Bignon, A relational approach of cooperation in building design,in: 8th Int. Conf. Concurr. Enterprising, Rome, Italy, 2002.

[35] S. Wallner, P. Von Both, BIM Tools Overview Target group-and process-oriented examination of free BIM tools, eCAADe 35. 1 (2017) 137-146.

[36] V. Bolshakova, G. Halin, P. Humbert, C. Boton, Digital Synchronous Collaboration Workspace and 3D Interactions for an AEC Project. Decision-Making Scenario Evaluation, CDVE 2017. 10451 (2017) 168-176. doi:10.1007/978-3-319-66805-5. 